\title{
Optimization of Energy Management for Charged Storage of a PV System by the Fuzzy Logic Technique
}

\author{
Anju Jolly \\ PG Student \\ Department of Electrical and \\ Electronics Engineering \\ Karunya University, Coimbatore
}

\author{
F.T. Josh \\ Assistant Professor \\ Department of Electrical and \\ Electronics Engineering \\ Karunya University, Coimbatore
}

\begin{abstract}
The reliability and efficiency of a photovoltaic system depends mainly on its energy management system which is done by the proper management and distribution of PV voltage to the battery and to the load to avoid the shortage of power. Our project concerns with the Optimization of energy management for charged storage of a PV system by the fuzzy logic technique ensure a longer battery life, and the energy distribution available from the photovoltaic array and the batteries. The results obtained that the fuzzy logic control maintains the battery voltage almost stable at the end phase of charging and discharging.
\end{abstract}

\section{Keywords}

Energy Management, Stand-Alone Photovoltaic Systems (SAPVS), Battery, Fuzzy Logic, Fuzzy Controller, State of charge, Maximum power point tracker (MPPT), Perturbation and Observation $(\mathrm{P} \& \mathrm{O})$ algorithm..

\section{INTRODUCTION}

The majority of the world's energy sources came from conventional sources-fossil fuels such as coal, natural gases and oil. Due to the large exploitation of these fuel leads to the decrease in their quantity and after a few years it will soon depleted. Also the use of conventional fuel causes pollution and global warming. This problems lead to the impressive growth of the renewable energy sector. One of such sector is photovoltaic industry.

Due to this number of PV installations increases day by day. Since the initial cost of the PV system is high the installed system must be reliable and provide maximum output during their life cycle. One of the major problems associated with the use of renewable energy is the non availability of the power continuously. To build a reliable system we must provide the power continuously for that we have to provide an energy storage device which is mainly battery.

The mastering of the performance of a Stand Alone Photovoltaic System (SAPVS) is done through the control and management of the energy of the system. The energy management of a PV system must have the following features:

- $\quad$ Produce a maximum power from the photovoltaic panel.

- Protecting the battery against deep discharging and the overcharging.

- $\quad$ Satisfy the energy needs of the user by avoiding energy shortage.
We aim by our study to design and implement an energy management algorithm for SAPVS. In this work we designed a maximum power point tracking (MPPT) algorithm to track the power from PV panel. After the modelization of the storage stage, we introduce a new technique, namely fuzzy logic which we use to design a fuzzy controller for batteries. That will allow us to optimize the management of the storage system ensuring a longer battery life and minimizing the potential malfunction of the elements by maintain the battery voltage within the acceptable range [10].

\section{BLOCK DIAGRAM}

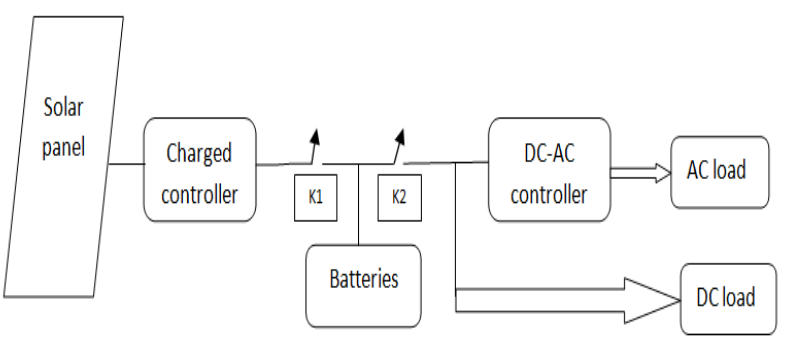

Fig 1 Block diagram of the system

This is the basic block diagram of the system. The power from the solar panel is given to the charged controller which includes the MPPT, DC-DC converter and is fed to the load and the battery depending upon the operation of the switching device which is controlled using the fuzzy logic controller depending upon the given criterion [2]. The load which can be either DC or AC but in our work we used a DC load. For connecting the $\mathrm{AC}$ load just use the inverter circuit

\section{MODELLING OF THE PV PANEL}

\subsection{Modelling equations}

We have modelled a 30W PV panel. The modelling equations of the PV panel is as follows [6]

The Iph represents the cell photo current; $\mathrm{Rj}$ is used to represent the non-linear impedance of the $\mathrm{p}$-n junction; Rsh and Rs are used to represent the intrinsic series and shunt resistance of the cell respectively. Usually the of Rsh value is very large and that of Rs is very small so they are usually neglected to simplify the analysis [12] .PV cells are grouped in larger units called PV modules which are further interconnected in series-parallel configuration to form PV 
arrays or PV generators. The PV mathematical model used to simplify our PV array is represented by the equation

$\mathrm{I} 0=\mathrm{n}_{\mathrm{p}} \mathrm{I}_{\mathrm{ph}}-\mathrm{n}_{\mathrm{p}} \mathrm{I}_{\mathrm{rs}}\left[\exp \left(\frac{\mathrm{q}}{\mathrm{KTA}} * \frac{\mathrm{V} 0}{\mathrm{n}_{\mathrm{s}}}\right)-1\right]$

where I0 is the PV array output current; V0 is the PV array output voltage; $n_{s}$ is the number of cells in series and $n_{p}$ is the number of cells in parallel; $q$ is the charge of an electron; $k$ is the Boltzmann's constant; A is the $\mathrm{p}-\mathrm{n}$ junction ideality factor; $\mathrm{T}$ is the cell temperature (K); Irs represents the cell reverse saturation current. Factor A determines the cell deviation from the ideal p-n junction characteristics; it ranges between $1-5$ but for our case $\mathrm{A}=2.46$.

The Irs reverse saturation current varies with temperature according to the following equation [3]:

$$
\mathrm{I}_{\mathrm{rs}}=\mathrm{I}_{\mathrm{rr}}\left[\frac{T}{T_{r}}\right]^{3} \exp \left(\frac{q E_{G}}{K A}\left[\frac{1}{T_{r}}-\frac{1}{T}\right]\right)
$$

Where $T_{r}$ is the cell reference temperature, Irr is the cell reverse saturation temperature at $T_{r}$ and $E_{G}$ is the band gap of the semiconductor ie silicon.[11]

The temperature of the energy gap of the semi conductor is given by:

$E_{G}=E_{G}(0)-\frac{\alpha T^{2}}{T+\beta}$

The photo current $\mathrm{I}_{\mathrm{ph}}$ depends on the solar radiation and cell temperature as follows:

$\mathrm{I}_{\mathrm{ph}}=\left[\mathrm{I}_{s c r}+K_{i}\left(T-T_{r}\right)\right] \frac{s}{100}$

Where $\mathrm{I}_{s c r}$ the cell is short-circuit current at reference radiation and temperature, $\mathrm{S}$ is the solar radiation in $\mathrm{mW} / \mathrm{cm} 2$ and $\mathrm{Ki}$ is the short circuit current temperature coefficient. The PV power can be calculated using equation as follows:

$\mathrm{P}=\mathrm{IV}=\mathrm{n}_{\mathrm{p}} \mathrm{I}_{\mathrm{ph}} \mathrm{V}\left[\left(\frac{\mathrm{q}}{\mathrm{KTA}} * \frac{\mathrm{V} 0}{\mathrm{n}_{\mathrm{s}}}\right)-1\right]$

\subsection{Simulation of the proposed model}

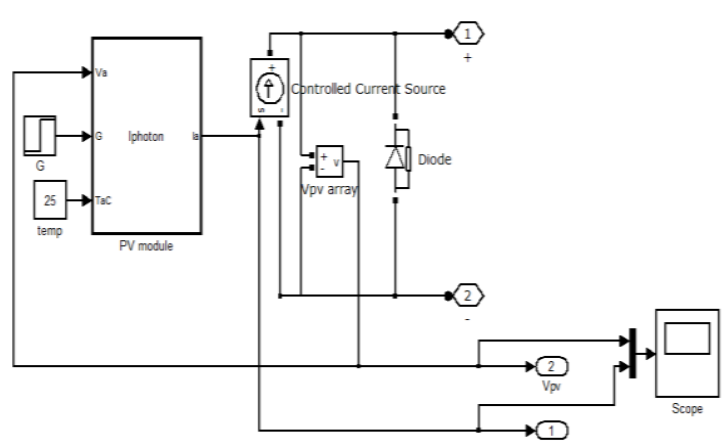

Fig 2 Simulation model of PV Panel

\section{MODELLING OF MPP TRACKING SYSTEM}

Maximum power point tracking (MPPT) is a technique that solar battery chargers, grid tie inverters and similar devices use to get the maximum possible power from PV array. Solar cells usually have a complex relationship between temperature, solar irradiation and total resistance that produces a non-linear output efficiency known as the I-V curve. It is the purpose of the MPPT system to sample the output of the cells and apply a resistance (load) to obtain maximum power for any given environmental conditions [8].

In this work we have just implemented the Perturbation and Observation ( $\mathrm{P} \& \mathrm{O})$ algorithm. The flow chart for the above algorithm is shown below.

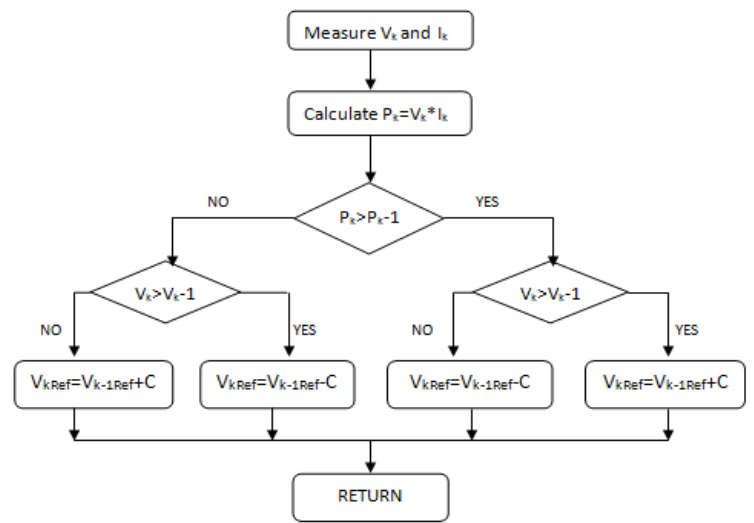

Fig 3 Flow chart of perturbs and observe algorithm

In this method, the controller adjusts the voltage by a small amount from the array and measures power; if power increases, further adjustments in that same direction are tried until power no longer increases. This method can result in oscillations of power output. It is likely to be referred to as a hill climbing method, because it is similar to the rise of the curve of power against voltage below the maximum power point, and it fall above that point. Perturb and observe is the most commonly used MPPT method due to its ease of implementation. Perturb and observe method may result in top-level efficiency, provided that a proper adaptive hill climbing strategy is adopted [1] [7].

\section{MODELLING OF BATTERY}

The lead-acid battery model was implemented based on a MATLAB model for a lead acid battery. It is having two modes of operation - charging and discharging modes. When the current to the battery is positive (or negative), the battery is in the charging (or discharging) mode. The following parameters are used for modeling the battery.

- $\quad \mathrm{SOC} 1$ is the initial state of charge,

- $\quad \mathrm{SOC}(\%)$ is the available charge.

- $\quad \mathrm{SOCm}$ is the maximum state of charge.

- $\mathrm{n}_{\mathrm{s}}$ is the number of $2 \mathrm{~V}$ cells connected in series.

- $\mathrm{D}$ is the self discharge rate of battery.

- $\mathrm{Kb}$ (no unit) is the charging and discharging battery efficiency.

Battery terminal voltage is given by:

$$
V_{\text {bat }}=V_{I}+I_{\text {bat }} R_{I}
$$

Here V1 and R1 both depend on the mode of battery operation and have different equations in each case. Battery current Ibat is positive when battery is in charge mode and negative when in discharge mode.

In charging mode, we can write the resistance and voltage as follows:

$R_{I}=R_{c h}=\left[0.758+\frac{0.139}{[1.06-S O C(t)] n_{s}}\right] \frac{1}{S O C_{m}}$ 
$\mathrm{V}_{\mathrm{I}}=\mathrm{V}_{c h}=[2+0.148 \operatorname{soc}(t)] n_{s}$

Where SOC (t) represents the current state of charge (\%), SOC $(t)$ is defined by a set of equations later.

In discharging mode, the resistance and voltage are written as follows:

$$
R_{I}=R_{d c h}=\left[0.19+\frac{0.1037}{[\operatorname{SOC}(t)-0.14] n_{s}}\right] \frac{1}{S O C_{m}}
$$

$\mathrm{V}_{\mathrm{I}}=\mathrm{V}_{d c h}=[1.926+0.124 \operatorname{soc}(t)] n_{s}$

To estimate the value of SOC $(t)$, the following equations have been used to describe them in the MATLAB model.

$$
\begin{aligned}
& \operatorname{SOC}(t+d t)=\operatorname{SOC}(t)[1- \\
& \left.\frac{D d t}{3600}\right]+\frac{K_{b}\left(V_{b a t} I_{b a t}-R_{I} I_{b a t}{ }^{2}\right) d t}{3600}
\end{aligned}
$$

In equation above, the time is assumed in seconds, so some terms must be divided by 3600 so that SOC is in Watt hour. By substituting $\mathrm{V}_{\text {bat }}$ as a function of $\mathrm{V}_{1}$, the value of SOC $(\mathrm{t})$ can be determined as shown.

$$
\begin{aligned}
& \operatorname{SOC}(t)=\quad \operatorname{SOC}(t-1)+\frac{1}{3600} \int_{t-1}^{t}\left[\frac{K_{b} V_{I} I_{\text {bat }}}{\operatorname{soc}_{m}}-\right. \\
& \operatorname{SOC}(t-1) D] d t
\end{aligned}
$$

There are namely: Rch, Rdch, Vch and Vdch. The input to the battery is the net current output from the PV panel and the output is the battery voltage, Vbat. In order to obtain $70 \mathrm{~V}, 35$ $2 \mathrm{~V}$ cells denoted by $\mathrm{n}_{\mathrm{s}}$ were used in the modeling. The maximum state of charge $\mathrm{SOC}_{\mathrm{m}}$ were set to 84. The discharge rate $\mathrm{D}$ and the efficiency $\mathrm{Kb}$ are set as $1.5 \times 10^{-5}$ and 0.8 . As the battery is in discharging or charging mode, it allows only one value for R1 and V1 to the equations [5].

\subsection{Simulation of battery}

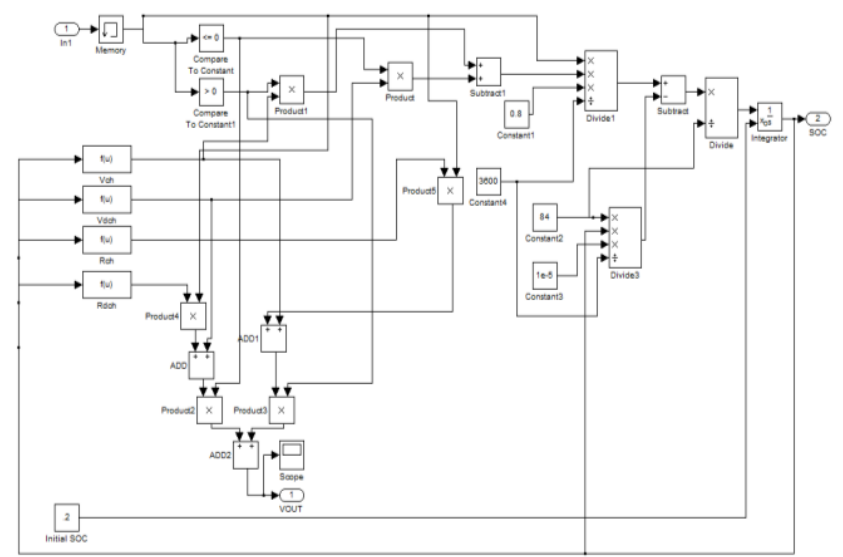

Fig 4 Simulation block of battery

\subsection{Battery output voltage}

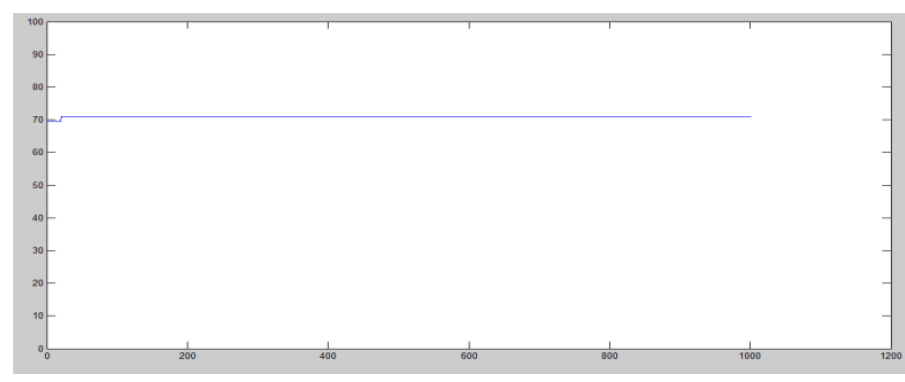

Fig 5 Battery output voltage

\section{BATTERY FUZZY CONTROLLER}

Several techniques are available for the implementation of the energy management algorithm. Among them we have chosen the fuzzy logic technique which has low power dissipation, an optimized cost, is reliable and stable. Fuzzy systems (FS) are based on fuzzy set theory and associated techniques pioneered by Lotfi Zadeh. It is a non-linear control method that attempts to apply the expert knowledge of an experienced user to the design of a fuzzy-based controller. Generally, as shown in figure 6.1, the Fuzzy Logic Controller (FLC) is composed by four main components:

a) The fuzzifier that converts crisp values into input fuzzy sets to activate rules.

b) The rules which define the controller behavior by using a set of IF-THEN statements.

c) The inference engine which converts input fuzzy sets into output fuzzy sets by applying the rules.

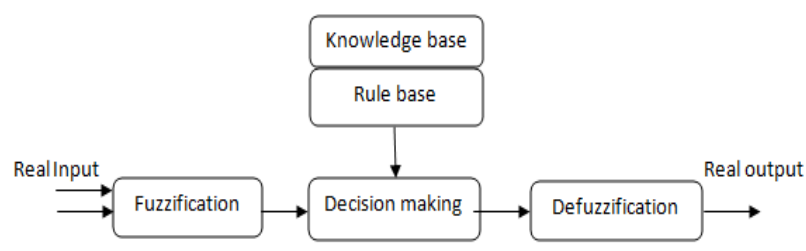

Fig 6 Block diagram of fuzzy

The rules describing the FLC operation are expressed as linguistic variables represented by fuzzy sets. The controller output was obtained by applying an inference mechanism [9].

\subsection{Designing of a battery fuzzy controller}

As the storage stage of the SAPV, in other words the battery, is one of the most sensitive blocks of the PV system, we have focused, as a first step, by elaborating an energy management for a SAPVS, on the energy storage management and battery controller. We propose 'an intelligent battery controller' based on a fuzzy algorithm.

The fuzzy controller which uses the Mamdani's FLC approach has two fuzzy inputs and two fuzzy outputs. The two inputs are the voltage battery VB and the photovoltaic current Ip.

The output variables are the control signal of the switch K1 located between the photovoltaic generator and the battery and the control signal of the switch K2 located between the battery and the load. After applying the rules, which 
corresponds to the fuzzification step, the method of the centre of gravity is used for the defuzzification in order to find the actual values of $\mathrm{K} 1$ and $\mathrm{K} 2$

To improve this fuzzy algorithm, we will insert in one hand VR the required voltage for connecting the load while the battery is charging, on the other hand, VF the overcharging voltage for disconnecting the PV array while the battery is discharging to the load. The battery voltage VB varies between $68 \mathrm{~V}$ and $76 \mathrm{~V}$. The linguistic variables considered are: $B U D$ for battery under-discharged, $B D$ battery discharged $B I C$ battery in charge, $B C$ battery charged and $B O C$ battery over-charged. The variation of the photovoltaic current Ip varies in the range of $-3 \mathrm{~A}$ to $+3 \mathrm{~A}$. The linguistic variables associated to Ip are: $N C$ for negative change and $P C$ for positive change. The range of the K1output variable is (0.5 to +0.5$)$. The range of the $\mathrm{K} 2$ output variable is $(-0.5$ to $+0.5)$.

The battery voltage is always fluctuating. As the lead-acid batteries are very sensitive to the time of the load it is necessary to charge them with a current corresponding to a voltage VB which is between two thresholds: the maximum threshold (the gasification voltage) and the minimum threshold (the sulphating voltage). In our work, we used a battery of $70 \mathrm{~V}$.

In order to understand how to use this table, we give the following example: If we assume that the battery is under discharged (BUD) and the photovoltaic current is negative $(N C)$ then the switch $\mathrm{K} 1$ will be On and K2 Off.[4]

\section{SIMULATION OF THE OVERALL SYSTEM}

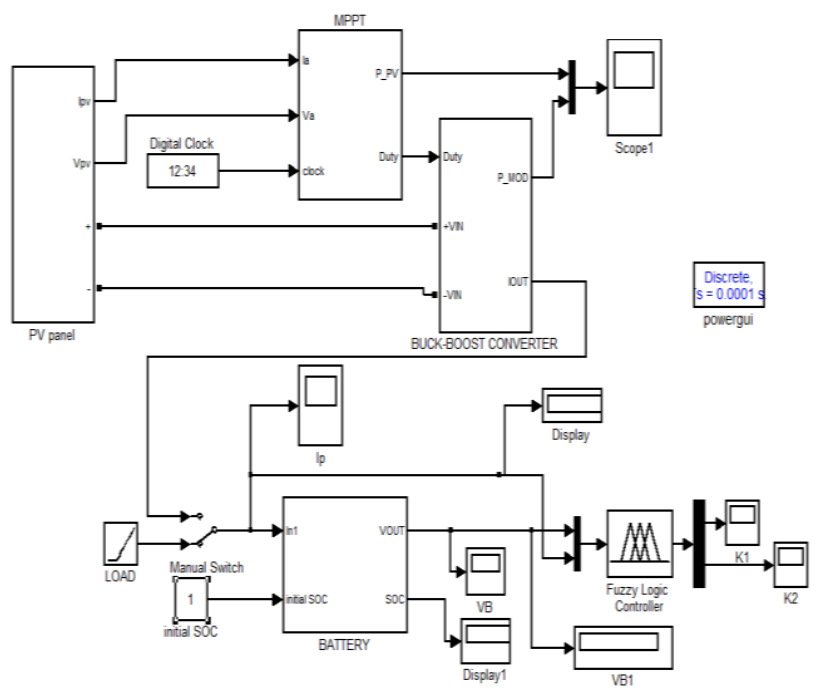

Fig 7 Simulation of entire SAPV system

\section{CASE 1:}

Battery is overcharged and battery is charging through PV

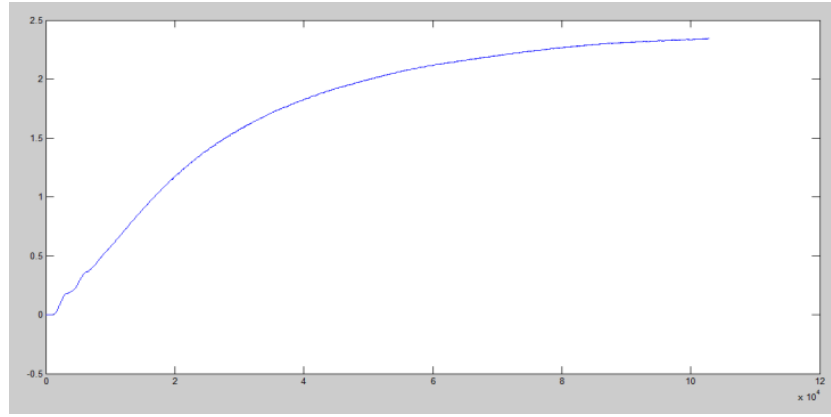

Fig 8 Charging current of battery (case1)

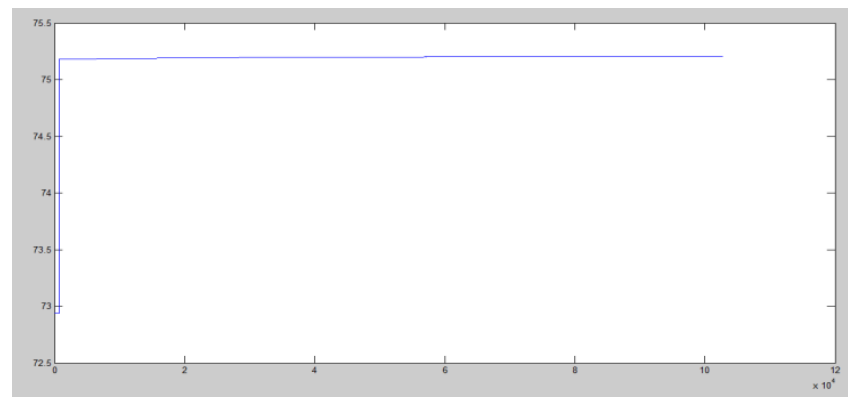

Fig 9 Battery output voltage (case1)

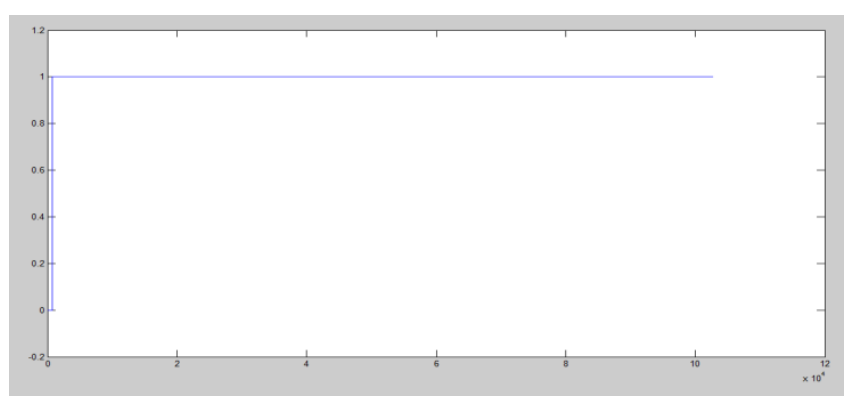

Fig 10 Operation of switch K1 (case1)

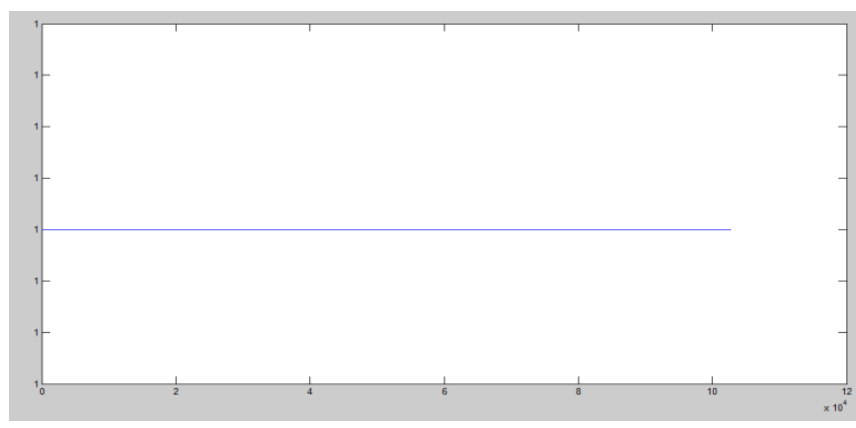

Fig 11 Operation of switch K2 (case1)

CASE 2:

Battery is undercharged and battery is charging through PV 


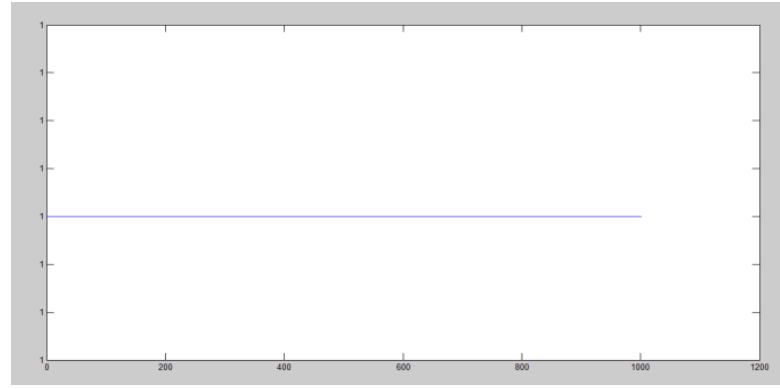

Fig 12 Operation of switch K1 (case2)

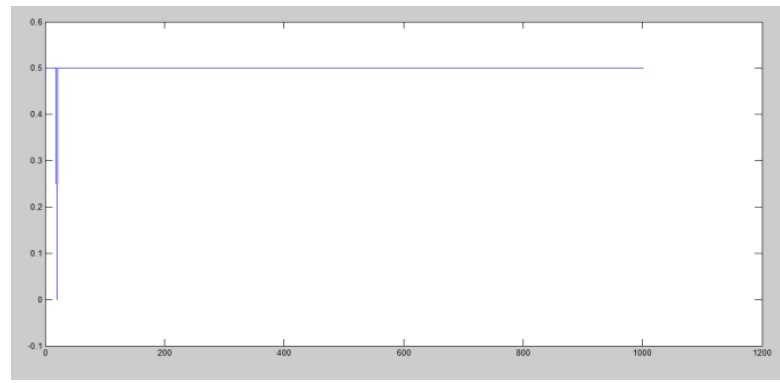

Fig 13 Operation of switch K2 (case2)

\section{CASE 3:}

Battery is undercharged and battery is discharging through the load

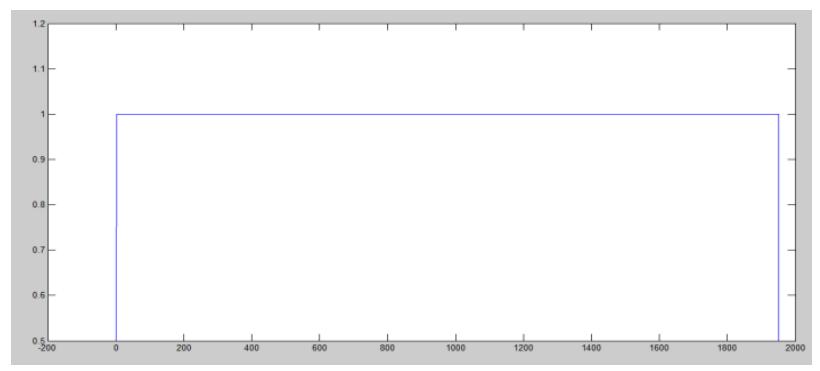

Fig 14 Operation of switch K1 (case3)

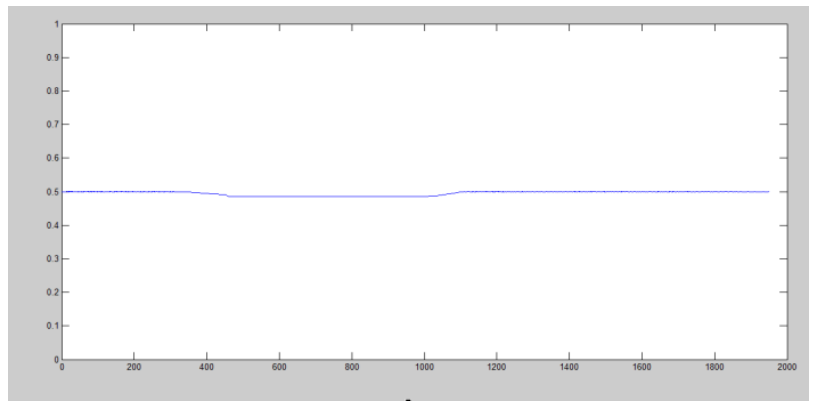

Fig 15 Operation of switch K2 (case3)

\section{CASE 4:}

Battery is overcharged and battery is discharging through the load

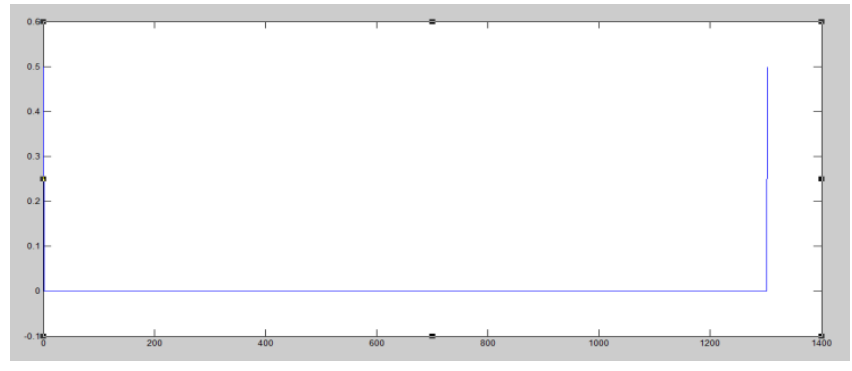

Fig 16 Operation of switch K1 (case4)

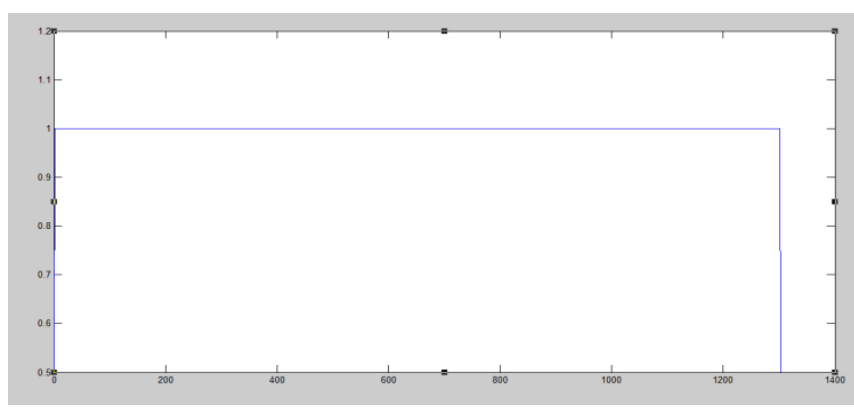

Fig 17 Operation of switch K2 (case4)

\section{CONCLUSION}

We have presented in this project the first version of a photovoltaic energy management system based on Fuzzy Logic Control technique. This technique allows us to manage with accuracy the switching mode of $\mathrm{K} 1$ and $\mathrm{K} 2$ which respectively control the battery charging mode and the feeding of the load. The transition time between the charging and discharging mode using this technique is very short comparing to the other techniques used in this field. In this project we have used lead-acid battery of $70 \mathrm{~V}$ capacity.

\section{REFERENCES}

[1] Arun KumarVerma, Bhim Singh and S.C Kaushik,( 2010) 'An Isolated Solar Power Generation using Boost Converter and Boost Inverter,' in Proc. National Conference on Recent Advances in Computational Technique in Electrical Engineering, SLITE, Longowal (India), paper 3011, pp.1-8.

[2] Athimulam Kalirasu, Subharensu Sekar Dash (2010) 'Simulation of Closed Loop Controlled Boost Converter for Solar Installation', Serbian Journal of Electrical Engineering Vol. 7, No. 1, 121-130.

[3] Atlas I.H, A.M Sharaf, (2007,) 'A photovoltaic Array Simulation Model for Matlab-Simulink GUI Environment' Proce. of IEEE International Conference on Clean Electrical Power, ICCEP Capri, Italy.

[4] Chekired F, C. Larbes, D.Rekioua, and F.Haddad,(2011) 'Implementation of MPPT fuzzy controller for photovoltaic systems on FPGA circuit,' Elsevier- Energy Procedia, vol.6, pp. 541-549.

[5] Chin CS, McBride W. (2011) 'Design, Modeling and Testing of a Standalone Single Axis Active Solar Tracker using MATLAB/Simulink'. Renewable Energy 36(11), 3075-3090. 
[6] Huan-Liang Tsai, Ci-Siang Tu, and Yi-Jie Su, ( 2008) 'Development of Generalized Photovoltaic Model Using MATLAB/SIMULINK', Proceedings of the World Congress on Engineering and Computer Science, San Francisco, USA.

[7] Hussein K.H., I. Muta, T. Hoshino, M. Osakada,( 1995.) 'Maximum photovoltaic power tracking: an algorithm for rapidly changing atmospheric conditions', IEE Proc.General Transaction Distribution, Vol. 142, No. 1

[8] Issam Houssamo, Fabrice Locment, and Maneula Sechilariu,( 2010) 'Maximum power tracking for photovoltaic power systems: Development and experimental comparison of two algorithms,' ElsevierRenewable energy, vol. 35, issue 10, pp. 2381-2387.

[9] Jiménez, C.J., Sanchez Solano, S., Barriga( 1995.) 'A Hardware implementation of a general purpose fuzzy controller'. IFSA'95, pp. 185-188,
[10] Mahrane A, M. Chikh, A. Chikouche. (2010) 'Optimization of energy management of a phoyovoltaic system by fuzzy logic technique'. Science Direct,Energy Procedia Volume 4, Number 1.

[11] Ramos Hernanz, JA., Campayo Martín, J.J. Zamora Belver, I., Larrañaga Lesaka, J., Zulueta Guerrero, E. Puelles Pérez, E.(2010), 'Modeling of Photovoltaic Module', International Conference on Renewable Energies and Power Quality (ICREPQ'10) Granada (Spain),

[12] Xiao W, W. G. Dunford, and A. Capel, (2004) 'A novel modeling method for photovoltaic cells', in Proc. IEEE 35th Annu. Power Electron. Spec. Conf. (PESC), vol.3, pp. 1950-1956. 